\title{
Effects of Phosphate Residues on the Excellent Emulsifying Properties of Phosphoglycoprotein Phosvitin
}

\author{
Akio Kato, Syoko Miyazaki, Akifumi Kawamoto \\ and Kunihiko KOBAYASHI \\ Department of Agricultural Chemistry, Faculty of Agriculture, \\ Yamaguchi University, Yamaguchi 753, Japan
}

Received May 27, 1987

\begin{abstract}
The effects of phosphate residues in phosvitin on its emulsifying properties were investigated. The emulsifying properties, especially the emulsion stability, of phosvitin were much superior to those of bovine serum albumin which is an excellent emulsifier. The emulsifying activity and emulsion stability of phosvitin were greatly decreased by the partial removal of phosphate with phosphatase and by the complete removal of phosphate with alkaline treatment. In addition, the emulsifying properties were decreased by the blocking of phosphate in phosvitin with calcium ion. These results suggest that the electrostatic repulsive force of phosphate in phosvitin significantly affects its emulsifying properties.
\end{abstract}

Chicken phosvitin is a highly phophorylated glycoprotein containing $10 \%$ phosphorus and $6.5 \%$ carbohydrates. ${ }^{1)}$ It is interesting that this highly hydrophilic protein is found in egg yolk. This suggests that phosvitin has an affinity for lipids. This protein seems to resemble a polyelectrolyte and to have a flexible conformation. ${ }^{2)}$ Thus, phosvitin is an interesting protein to use in investigating the relationship between structural and functional properties.

We have reported that the sialoglycoprotein ovomucin has a good emulsifying and foaming properties $^{3)}$ and that sialic acid is important in their functional properties. ${ }^{4)}$ Ovomucin contains about $10 \%$ terminal sialic acid residues. ${ }^{5}$ ) Thus, ovomucin closely resembles phosvitin as a polyanion-type protein. Therefore, a common information about the structural factors governing the functional properties of polyanion-type proteins may be obtained from the studies on the structural and functional properties of phosvitin.

This paper describes the effects of phosphate residues on the emulsifying properties of phosvitin.

\section{MATERIALS AND METHODS}

Materials. Ovalbumin was prepared from fresh egg white by the crystallization method in sodium sulfate, and was recrystallized five times. Bovine serum albumin was purchased from Sigma Chemical Co. (St. Louis, MO). All other reagents employed were of analytical grade.

Phosvitin preparations. Phosvitin was prepared from fresh egg yolk by the method of Mecham and Olcott. ${ }^{6}$ Phosvitin was further purified by ion exchange chromatography on a DEAE-Sephadex A-50 column $(3.0 \times 15 \mathrm{~cm})$

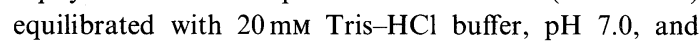
eluted by a linear salt gradient $(0 \sim 0.6 \mathrm{M} \mathrm{NaCl}$ in the equilibration buffer). The single peak eluted in a salt concentration of 0.4 to $0.5 \mathrm{M}$ was collected and lyophilized after dialysis against deionized water.

Measurement of molecular weight of phosvitin. $0.3 \mathrm{ml}$ of $0.1 \%$ phosvitin solution in $1 / 15 \mathrm{~m}$ phosphate buffer, $\mathrm{pH}$ 7.0 , containing $0.1 \mathrm{M} \mathrm{NaCl}$ was applied to a high performance gel chromatography using a TSK gel G3000SW column (Toyo Soda Co., $0.75 \times 60 \mathrm{~cm}$ ) at a flow rate of $0.3 \mathrm{ml} / \mathrm{min}$. Elution from the column was monitored with a low-angle laser light scattering photometer (LS-8, Toyo Soda Co.) and then with a precision differential refractometer (RI-8, Toyo Soda Co.). The molecular weight of phosvitin was estimated from the ratio of the height of the peak of the light scattering photometer to that of the refractometer by the method of Takagi and Hizukuri. ${ }^{7)}$ 


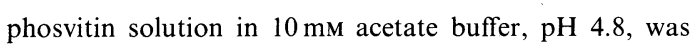
added 100 micrograms of phosphatase (acid type, Sigma Chemical Co., Type I). The phosphatase reaction was done at $37^{\circ} \mathrm{C}$ for $15 \mathrm{hr}$, and the dephosphorylated phosvitin thus obtained was lyophilized after dialysis against deionized water.

Alkaline treatment of phosvitin. $0.05 \%$ phosvitin solution in $0.25 \mathrm{~N} \mathrm{NaOH}$ was incubated at $35^{\circ} \mathrm{C}$ for $24 \mathrm{hr}$. After the reaction, a sample was dialyzed against deionized water and then lyophilized.

Phosphorus measurements. The phosphorus was measured by the method of Allen. ${ }^{8)}$

Measurement of emulsifying properties. The emulsifying properties of proteins were measured by the method of Pearce and Kinsella. ${ }^{9)}$ To prepare emulsion, $1 \mathrm{ml}$ of corn oil and $3 \mathrm{ml}$ of $0.1 \%$ protein solution in $100 \mathrm{~mm}$ phosphate

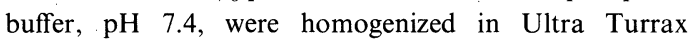
(Hansen \& Co., West Germany) at 12,000 rpm for $1 \mathrm{~min}$ at $20^{\circ} \mathrm{C}$. Fifty $\mu \mathrm{l}$ of emulsions were taken from the bottom of the container at $1 \mathrm{~min}$ intervals immediately after homogenization and were diluted to $1 / 100$ with $5 \mathrm{ml}$ of $0.1 \%$ SDS solution. The turbidity of the diluted emulsion was then measured at $500 \mathrm{~nm}$ with time. The emulsifying activity of proteins is expressed as the absorbance at $500 \mathrm{~nm}$ of the diluted emulsions immediately after homogenization. The emulsion stability of proteins is represented as the half-life period ( $\mathrm{min}$ ) of the resulting turbidity of the emulsion, estimating from the turbidity curves of emulsions. The effect of calcium ion on the emulsifying properties of

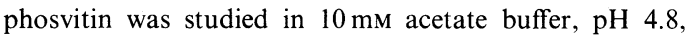
because precipitates occurred in phosphate buffer.

$C D$ analysis. The circular dichroism of phosvitin was measured with a Jasco Model J-20C spectropolarimeter at $20^{\circ} \mathrm{C}$. CD spectra were expressed in terms of the mean residue ellipticity in $\mathrm{deg} \cdot \mathrm{cm}^{2} \mathrm{dmol}^{-1}$. The accuracy of the data was improved by averaging 4 scans integrated with the data processor.

\section{RESULTS}

Phosvitin preparation eluted in a salt concentration of $0.4 \mathrm{M}$ to $0.5 \mathrm{M} \mathrm{NaCl}$ by DEAESephadex A-50 column chromatography contained $10.1 \%$ phosphorus and $53 \%$ serine residue in total amino acids. Thus, highly phosphorylated phosvitin was obtained. The homogeneity was checked and the molecular weight was measured by using the low-angle laser light scattering technique in combination with high performance gel chromatography.
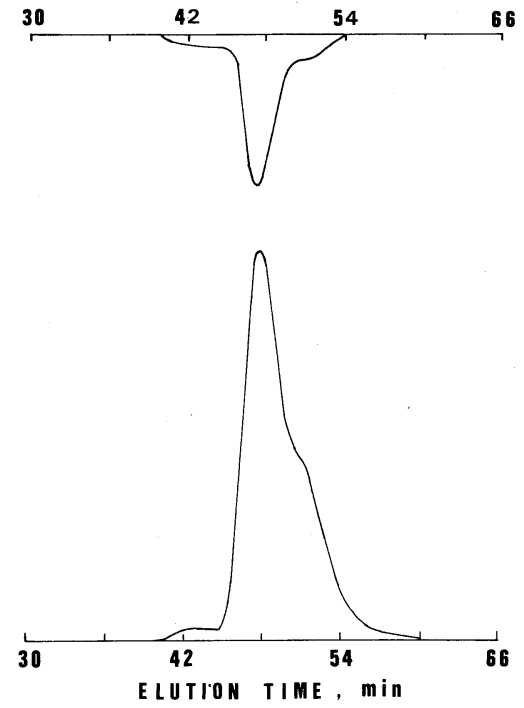

Fig. 1. High Performance Gel Chromatograms of Phosvitin Detected by Low-angle Laser Light Scattering Photometer (Top) and Precision Differential Refractometer (Bottom).

The gain setting for the light scattering photometer is 32 and that for the differential refractometer is 128 .

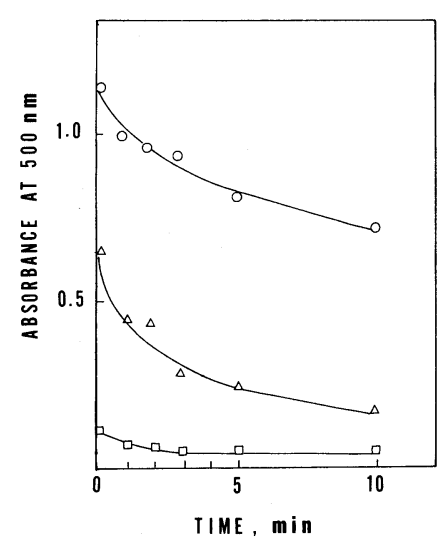

FIG. 2. Comparison of the Emulsifying Properties of Phosvitin, Serum Albumin, and Ovalbumin.

$\bigcirc$, phosvitin; $\triangle$, serum albumin; $\square$, ovalbumin.

Three populations of phosvitin were observed with gel chromatography (Fig. 1), $M_{r}$ $150,000,30,000$ and 15,000 in order of their elution from the column. The three populations represented $2.7 \%, 74.2 \%$ and $23.1 \%$ of the total phosvitin applied, based on an integration of the areas of peaks. 
Figure 2 shows the emulsifying properties of phosvitin, serum albumin and ovalbumin. The emulsifying activity and emulsion stability were calculated from the curves in Fig. 2. The emulsifying activity and emulsion stability of phosvitin were much higher than those of serum albumin, which is a protein with good emulsifying properties (Table I). In particular, the emulsion stability was excellent. In order to investigate the structural factors governing the excellent emulsifying properties of phosvitin, the effects of enzymatic and chemical dephosphorylation are described below.

Table II shows the degree of dephosphorylation during phosphatase-treatment of phosvitin. The maximal release of phosphate was $40 \%$ after the enzymatic reaction for $10 \mathrm{hr}$. The phosphate residues releasing by phosphatase treatment may be exposed at the surface of molecule, while other phosphate residues are probably buried in the interior of molecule.

Figure 3 shows the effects of phosphatase treatment on the emulsifying properties of

Table I. Emulsifying ACtivities AND Emulsion Stabilities of Phosvitin, Serum Albumin and Ovalbumin

\begin{tabular}{lcc}
\hline Proteins & $\begin{array}{c}\text { Emulsifying } \\
\text { activity } \\
\left(\mathrm{OD}_{500}\right)\end{array}$ & $\begin{array}{c}\text { Emulsion } \\
\text { stability } \\
(\mathrm{min})\end{array}$ \\
\hline Phosvitin & $1.150 \pm 0.042$ & $18.0 \pm 0.8$ \\
Serum albumin & $0.650 \pm 0.020$ & $3.0 \pm 0.1$ \\
Ovalbumin & $0.130 \pm 0.008$ & $1.5 \pm 0.1$ \\
\hline
\end{tabular}

Reported values are mean \pm standard deviation, $n=5$.

Table II. Degree of Dephosphorylation of Phosvitin by Phosphatase

\begin{tabular}{cc}
$\begin{array}{c}\text { Reaction time } \\
(\mathrm{hr})\end{array}$ & $\begin{array}{c}\text { Percentage of dephosphorylation } \\
{ }^{a}\end{array}$ \\
\hline 1 & 32 \\
5 & 37 \\
10 & 40 \\
15 & 40 \\
20 & 40 \\
\hline
\end{tabular}

a The degree of dephosphorylation was represented as a percentage of the content of phosphate released with alkaline treatment $\left(0.25 \mathrm{~N} \mathrm{NaOH}, 35^{\circ} \mathrm{C}, 24 \mathrm{hr}\right)$.

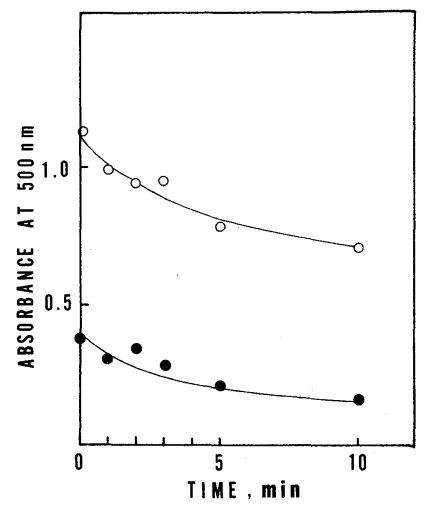

FIG. 3. Effects of Phosphatase Treatment on the Emulsifying Properties of Phosvitin.

$\bigcirc$, native; 9 , phosphatase treated.

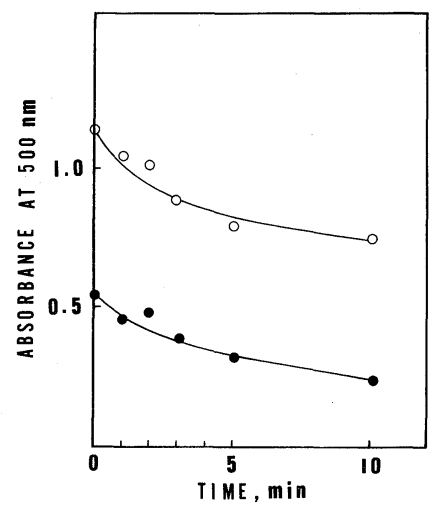

FIG. 4. Effects of Alkaline Treatment on the Emulsifying Properties of Phosvitin.

$\bigcirc$, native;, alkaline treated.

phosvitin. The emulsifying activity and emulsion stability were greatly decreased by phosphatase treatment. This suggests that the phosphate residues in phosvitin plays an important role in the emulsifying properties.

Figure 4 shows the effects of alkaline treatment on the emulsifying properties of phosvitin. All of the phosphate residues in phosvitin were released by alkaline treatment. The emulsifying properties of phosvitin were greatly decreased by alkaline treatment. Phosvitin may be subject to alkaline denaturation, in addition to dephosphorylation by alkaline treatment. It is known that the emulsifying properties of proteins are improved as de- 
naturation proceeds. ${ }^{10)}$ Therefore, the decrease in the emulsifying properties is not as large as expected from complete dephosphorylation, because it may be compensated for by the increase in the flexibility or the expose of hydrophobic residues due to the effect of denaturation.

Figure 5 shows the effects of the addition of calcium ion on the emulsifying properties of phosvitin. The emulsifying properties were

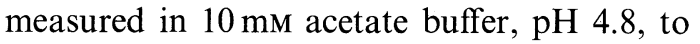
avoid the formation of precipitates. Therefore, the emulsifying activity is somewhat higher than that in the phosphate buffer described above. The emulsifying properties of phosvitin

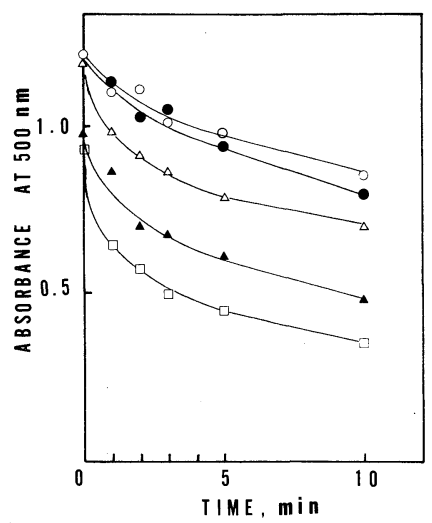

FIG. 5. Effects of the Addition of Calcium Ion on the Emulsifying Properties of Phosvitin.

О, $0 \mathrm{~mm}$ ○, $5 \mathrm{~mm} ; \triangle, 10 \mathrm{~mm} ; \boldsymbol{\Delta}, 15 \mathrm{~mm} ; \square, 20 \mathrm{~mm}$. were decreased with the concentration of calcium ion. The effects of the addition of calcium ion were large above $10 \mathrm{~mm}$ concentration. This may be because calcium ion is used to form calcium acetate in acetate buffer below $10 \mathrm{~mm}$ concentration. The emulsion stability was greatly decreased by the addition of calcium ion, while the emulsifying activity was not decreased so much. The emulsifying activity of proteins is increased with increasing salt concentrations. ${ }^{11)}$ Therefore, the emulsifying activity of phosvitin was not decreased so much in the presence of calcium ion because of the compensation for the decrease due to the blocking of phosphate residues. Despite the

TABle III. EmUlsifying ACtivities AND

Emulsion Stabilities of Phosphatasetreated AND Alkaline-treated Phosvitin, and Calcium-Binding Phosvitin

\begin{tabular}{lcc}
\hline Phosvitin & $\begin{array}{c}\text { Emulsifying } \\
\text { activity } \\
\left(\mathrm{OD}_{500}\right)\end{array}$ & $\begin{array}{c}\text { Emulsion } \\
\text { stability } \\
(\mathrm{min})\end{array}$ \\
\hline Phosphatase-treated & $0.400 \pm 0.014$ & $3.0 \pm 0.1$ \\
Alkaline-treated & $0.550 \pm 0.021$ & $7.0 \pm 0.2$ \\
Calcium addition & & \\
$0 \mathrm{~mm}$ & $1.210 \pm 0.042$ & $18.0 \pm 0.8$ \\
$5 \mathrm{mM}$ & $1.190 \pm 0.054$ & $16.0 \pm 0.6$ \\
$10 \mathrm{mM}$ & $1.160 \pm 0.040$ & $14.0 \pm 0.5$ \\
$15 \mathrm{mM}$ & $0.980 \pm 0.015$ & $10.0 \pm 0.3$ \\
$20 \mathrm{mM}$ & $0.948 \pm 0.038$ & $4.0 \pm 0.5$ \\
& &
\end{tabular}

Reported values are mean \pm standard deviation, $n=5$.

a)

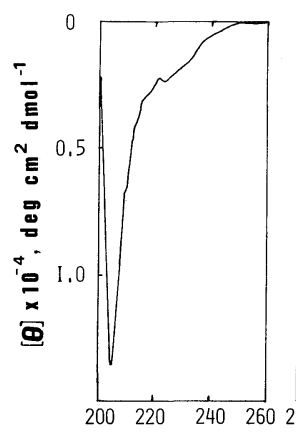

b)

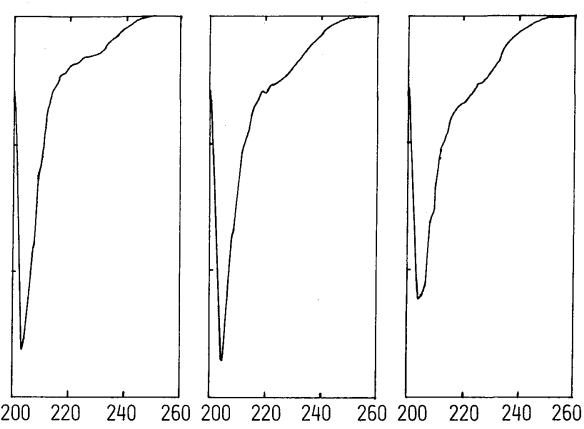

WAVE LEN GTH , n m

FIG. 6. CD Spectra of Native and Modified Phosvitin.

a) native; b) phosphatase treated; c) $10 \mathrm{~mm} \mathrm{CaCl}_{2}$ added; d) $20 \mathrm{~mm} \mathrm{CaCl}_{2}$ added. 
effects of salt concentration, the emulsion stability was significantly decreased by the addition of calcium ion. These effects of the modification of phosphate residues in phosvitin are summarized in Table III. The emulsifying properties of phosvitin were decreased by all modification of phosphate residues, suggesting the importance of phosphate residues in emulsion formation and stabilization.

The effects of the modification of phosphate residues on the structure of phosvitin were studied by $C D$ analysis. Figure 6 shows the CD spectra of native and modified phosvitin. The CD spectrum of native phosvitin indicates the pattern of typical unfolding proteins. The phosphatase treatment did not affect the CD spectrum. On the other hand, the addition of calcium ion caused a slight increase in the amplitude near $220 \mathrm{~nm}$, suggesting a partial formation of secondary structure. However, these changes are mild, not drastic. Therefore, the conformation of phosvitin as a whole seems to remain unfolded. Thus, the decreases in the emulsifying properties may be mainly due to the effects of phosphate residues and partially due to the conformation.

\section{DISCUSSION}

There are some reports on the fractionation of phosvitin by chromatographic and electrophoretic analysis. ${ }^{12 \sim 14)}$ However, resolution of the various phosvitin components into discrete peaks seems to be difficult, because of some heterogeneity resulting from different phosphorylation and size. Itoh et $a l{ }^{13)}$ have reported that phosvitin consists of alpha-phosvitin, with less phosphorus and beta-phosvitin, with more phosphorus. Wallace and Morgan ${ }^{14)}$ have reported that chicken phosvitin contains at least five major components, $M_{r} 40,000,33,000,18,000,15,000$ and 13,000. Phosvitin, prepared here may be beta-phosvitin, as judged from the phosphorus content and molecular weight. The molecular weight of phosvitin was determined by lowangle laser light scattering technique. This method is superior to size-exclusion chromatography and SDS-acrylamide gel electrophoresis for unfolded proteins such as phosvitin, because it is free from the ambiguity associated with methods depending on the molecular sieving effect. Thus, the molecular weight of major populations may be close to the true one.

It was found that phosvitin has excellent emulsifying properties and that the phosphate residues of phosvitin are important for its emulsifying properties. Interestingly, the decreases in the emulsion stability are greater than those in the emulsifying activity upon the removal or blocking of phosphate. In a previous paper, ${ }^{4)}$ large decreases in the emulsifying properties of ovomucin are observed upon the removal of sialic acids. Thus, polyaniontype proteins such as ovomucin and phosvitin decrease commonly in their emulsifying properties by the removal of sialic acid and phosphate polyanion, respectively. We have proposed that protein hydrophobicity and flexibility are important structural factors govering the emulsifying properties of proteins. In addition to these factors, the repulsive force of proteins seems to contribute to the emulsifying properties. Petrowski ${ }^{15}$ proposed that the electrostatic repulsive force of emulsion particles contributed to stabilize the emulsion droplets. This may also be the case for protein emulsions. Thus, the repulsive force of phosphate polyanion seems to be important in the emulsion stability. On the other hand, phosvitin is an unfolding protein and may be a flexible molecule, as shown by the CD spectrum (Fig. 6). This structural feature seems to contribute to exposing the hydrophobic regions and to facilitate the emulsion formation.

\section{REFERENCES}

1) G. Taborsky and C. -C. Mok, J. Biol. Chem., 242, 1495 (1967).

2) K. Gizzuti and G. E. Perlmann, J. Biol. Chem., 245, 2573 (1970).

3) A. Kato, S. Oda, Y. Yamanaka, N. Matsudomi and K. Kobayashi, Agric. Biol. Chem., 49, 3501 (1985).

4) A. Kato, N. Miyachi, N. Matsudomi and K. 
Kobayashi, Agric. Biol. Chem., 51, 641 (1987).

5) L. L. Young and F. A. Gardner, J. Food Sci., 37, 8 (1972).

6) D. K. Mecham and H. S. Olcott, J. Am. Chem. Soc., 71, 3670 (1949).

7) T. Takagi and S. Hizukuri, J. Biochem., 1984, 1459.

8) R. J. L. Allen, Biochem. J., 34, 858 (1940).

9) K. N. Pearce and J. E. Kinsella, J. Agric. Food Chem., 26, 716 (1978).

10) A. Kato, N. Tsutsui, N. Matsudomi, K. Kobayashi and S. Nakai, Agric. Biol. Chem., 45, 2755 (1981).

11) C. E. Swift and W. L. Sulzbacher, Food Technol. (Chicago), 17, 106 (1963).

12) Y. Abe, T. Itoh and S. Adachi, J. Food Sci., 47, 1903 (1982).

13) T. Itoh, Y. Abe and S. Adachi, J. Food Sci., 48, 1755 (1983).

14) R. A. Wallace and J. P. Morgan, Biochem. J., 240, 871 (1986).

15) G. E. Petrowski, Adv. Food Res., 22, 309 (1976). 